Gut, 1987, 28, 13-16

\title{
Effect of cisapride on the gastrointestinal transit of a solid meal in normal human subjects
}

\author{
C A EDWARDS, S HOLDEN, C BROWN, AND N W READ \\ From the Clinical Research Unit, Royal Hallamshire Hospital, Sheffield
}

SUMmaRY The effect of cisapride, a new gastrointestinal prokinetic agent, on the transit of a standard meal through the stomach, small intestine and colon was studied in 10 normal subjects. Cisapride had no significant effect on gastric emptying but decreased mouth to caecum transit time $(p<0 \cdot 01)$. Stool weight and frequency were not significantly increased but the time for the first appearance of stool markers and the arrival of $20 \%$ and $50 \%$ of stool markers was decreased after cisapride $(\mathrm{p}<0 \cdot 05)$.

Cisapride is a new gastrointestinal prokinetic agent which is thought to act selectively on the gut by releasing acetylcholine from the myenteric plexus. Unlike other gastrokinetic agents, it has a minimal action on dopamine receptors, ${ }^{1}$ and is therefore free of the serious side effects of other gastrokinetic agents. It also has none of the general effects on other systems seen with drugs that act directly on muscarinic cholinoreceptors. Studies in animal models ${ }^{23}$ and in $\operatorname{man}^{2}{ }^{4}$ have indicated that it may enhance motor activity in the stomach, small intestine, and colon, and has a wider spectrum of activity than previous gastrokinetic agents. We have developed a technique for screening the effects of drugs on motor activity in the gut by measuring the transit of a single solid meal through the stomach, small intestine and colon. ${ }^{5}$ We have used this method to investigate the action of cisapride in normal volunteers.

\section{Methods}

\section{SUBJECTS}

Paired studies were carried out in a total of 10 healthy male volunteers, aged 19-26 years. All subjects gave written informed consent and the protocols were approved by the Ethical Subcommittee of the Sheffield Area Health Authority.

TRANSIT MEASUREMENTS

The transit of a solid meal through the stomach and small intestine ${ }^{5}$ was measured in each subject after

Address for correspondence: Dr C A Edwards. Clinical Research Unit. H Floor, Royal Hallamshire Hospital, Sheffield S10 2JF.

Received for publication 30 May 1986. ingestion of cisapride or a visually identical placebo. The studies were separated by a week, the subject did not know whether he was taking the active drug or the placebo and the order of the studies was randomised. After an overnight fast, each subject ingested one tablet of cisapride $(10 \mathrm{mg})$ or placebo and 30 minutes later ate a solid meal consisting of three hot dog sausages, $150 \mathrm{~g}$ mashed potato, $120 \mathrm{~g}$ baked beans, a dessert of homogenised pineapple sweetened with sucrose and thickened with custard powder $(75 \mathrm{~g})$ and $50 \mathrm{ml}$ water. The total energy intake was $536 \mathrm{kcals} .25 \mu \mathrm{Ci}{ }^{99} \mathrm{Technetium} \mathrm{sulphur}$ colloid were incorporated into the mashed potato, along with 50 segments $(4 \mathrm{~mm} \times 2 \mathrm{~mm})$ of radioopaque polyvinyl tubing.

The subject lay supine on a couch and gastric emptying was monitored with a single crystal scintillation detector positioned over the fundus of the stomach. ${ }^{5}$ Counts were measured for one minute every five minutes until the activity (corrected for decay) had decreased to one third of the original value.

Mouth to caecum transit time of the head of the meal was monitored by measuring the time taken between ingestion of the meal and the rise in concentration of hydrogen in the breath that occurred when the unabsorbable oligosaccharides in the baked beans in the meal reached the colon and were fermented by colonic bacteria. Samples of end expiratory air were taken before ingestion of the meal and at 5 minutes intervals thereafter and the hydrogen concentration in each sample was measured with an electrochemical detector (GMI Medical Limited, Renfrew, UK) ${ }^{5}$ In the majority of cases (17 out of 20) baseline variation was no more 
than $4 \mathrm{ppm}$. The mouth to caecum transit time of the head of the meal was taken as the time when the hydrogen level in the breath rose by at least $6 \mathrm{ppm}$ above basal for a sustained period of at least 30 minutes (six consecutive readings).

Three and a half hours after the ingestion of the meal, the subject took a further one tablet of cisapride or placebo.

Blood pressure, pulse rate, and respiration rates were monitored every 30 minutes throughout the study. All stools passed for a $72 \mathrm{~h}$ period from the beginning of the study were collected. During this time the subject was instructed to take one tablet $(10 \mathrm{mg})$ of either placebo or cisapride three times a day before meals. The times of ingestion of the tablets and the passage of stools were noted.

Each stool sample was weighed, inspected for consistency (pellet, formed, loose, or liquid) and the number of radio-opaque markers was determined by radiography. ${ }^{5}$ The times taken for the first marker, $20 \%$ and $50 \%$ of the markers to be voided was noted.

STATISTICAL ANALYSIS

The data was analysed by Wilcoxon's rank sum test.

\section{Results}

TRANSIT MEASUREMENTS

Cisapride had no significant effect on the profile for gastric emptying and on values for the half times for gastric emptying (Figure). It decreased the transit time, however, of the head of the meal through the small bowel in every subject $(p<0.01$, Table, Figure).

The time for the first stool markers to appear in the stools and for $20 \%$ and $50 \%$ of the markers to be voided was significantly shorter after cisapride $(\mathrm{p}<0.01$, Table). The total stool weight for 72 hours was increased in eight of nine subjects and the frequency of defecation was greater in six out of 10 subjects (Table, Figure), but these results were not statistically significant.

\section{CARDIORESPIRATORY MEASUREMENTS}

There was no significant change in average heart rate, systolic and diastolic pressures and respiration rate over the five to six hour study day during administration of cisapride compared with placebo (Table). No unwanted effects were reported by any of our subjects.

\section{t1/2 Gastric Mouth to caecum Passage of 50\% emptying
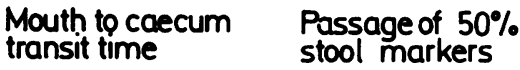

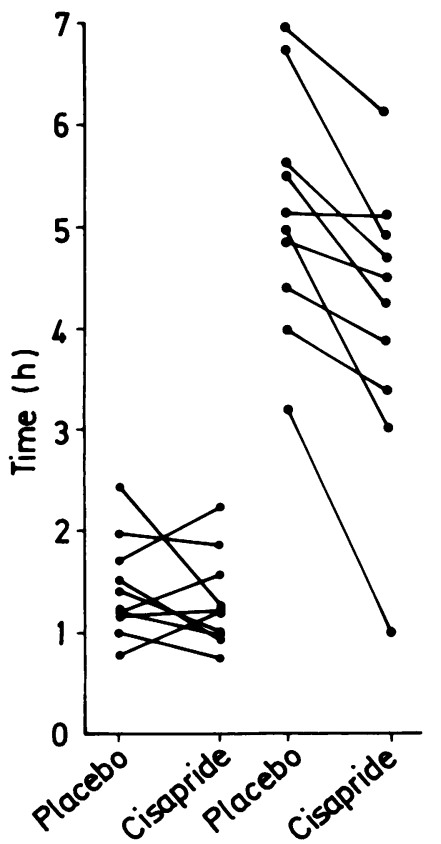

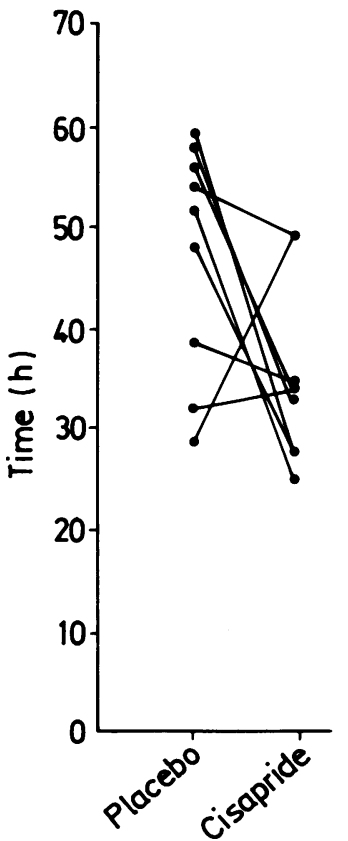

Frequency of defecation

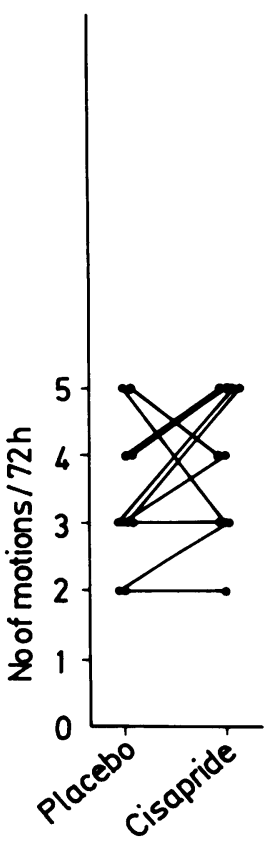

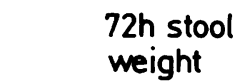

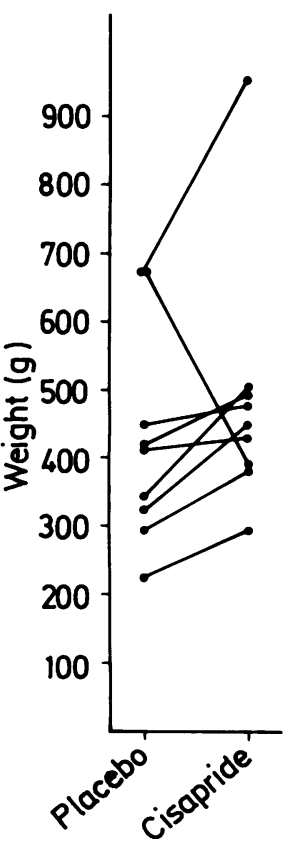

Figure Effect of cisapride (10 mg po), on the gastric emptying, mouth to caecum time, time of passage of $50 \%$ stool markers, frequency of defecation and $72 \mathrm{~h}$ stool weight following a standard solid meal in normal subjects. 
Table Effect of cisapride on the transit of a solid meal through the stomach small intestine and whole gut, and on cardiorespiratory function in 10 normal male volunteers

\begin{tabular}{|c|c|c|c|}
\hline & $\begin{array}{l}\text { Placebo } \\
\text { Mean SEM }\end{array}$ & $\begin{array}{l}\text { Cisapride } \\
\text { Mean SEM }\end{array}$ & $p$ \\
\hline Gastric emptying $\left(t_{2}^{1}=\min \right)$ & $76 \cdot 6 \pm 3 \cdot 2$ & $78 \cdot 5 \pm 8 \cdot 7$ & NS \\
\hline Mouth to caccum transit (min) & $310 \cdot 6 \pm 22 \cdot 4$ & $248 \cdot 4 \pm 26 \cdot 9$ & $\mathrm{p}<0 \cdot(01$ \\
\hline First appearance of stool markers (h) & $26 \cdot 2 \pm 3 \cdot 2$ & $14 \cdot 3 \pm 3 \cdot 2$ & $\mathrm{p}<0 \cdot(05$ \\
\hline Arrival of $50 \%$ of stool markers $(n=9)(h)$ & $45 \cdot 2 \pm 3 \cdot 3$ & $34 \cdot 7 \pm 3 \cdot()$ & $p<0 \cdot(05$ \\
\hline Frequency of defecation (in $72 \mathrm{~h}$ ) & $3 \cdot 4 \pm 0 \cdot 3$ & $3 \cdot 9 \pm 0 \cdot 4$ & NS \\
\hline Total stool wt (in $72 \mathrm{~h})(\mathrm{g})(\mathrm{n}=9)$ & $425 \cdot 0 \pm 52 \cdot 7$ & $487 \cdot() \pm 59 \cdot()$ & NS \\
\hline \multicolumn{4}{|l|}{ Mean blood pressure (mmHg) } \\
\hline Diastolic & $113 \cdot 3 \pm 1 \cdot 4$ & $114 \cdot 3 \pm 1 \cdot 6$ & NS \\
\hline Systolic & $77 \cdot 4 \pm 1 \cdot 4$ & $77 \cdot 3 \pm 2 \cdot 1$ & NS \\
\hline Respiration rate (breaths per min) & $15 \cdot 9 \pm 0 \cdot 4$ & $17 \cdot 9 \pm 0 \cdot 7$ & NS \\
\hline Heart rate (beats per min) & $62 \cdot 7 \pm 2 \cdot 3$ & $68 \cdot() \pm 2 \cdot 3$ & NS \\
\hline
\end{tabular}

Mean \pm SEM.

Probability calculated by Wilcoxon's rank sum test.

\section{Discussion}

Our results have shown that cisapride decreased the transit time of a solid meal through the small intestine and colon with no apparent effect on gastric emptying. Cisapride has previously been reported to accelerate the emptying of a barium meal $^{6}$ and a radiolabelled solid meal ${ }^{7}$ from the stomach of dyspeptic patients. A further study, however, showed that cisapride accelerated the emptying of solids and liquids in dyspeptic patients only when these values were abnormally slow. Thus, if we assume our subjects were normal, it is unlikely that we would observe any significant acceleration of gastric emptying with cisapride.

It is possible, however, that the use of the single scintillation detector is insufficiently sensitive to pick up small changes in gastric emptying. Also our subjects were supine which is not the usual position after eating. The dose and mode of administration of cisapride are other possible influences on its effect on gastric emptying. Both oral $(>4 \mathrm{mg} \mathrm{po})^{79}$ and intravenous $(>2 \mathrm{mg})^{7}$ have been shown to accelerate gastric emptying in dyspeptic patients, however, and intravenous doses $(8 \mathrm{mg})$ did not accelerate gastric emptying in patients who had normal emptying rates.

Despite the lack of effect on gastric emptying, cisapride accelerated the small bowel transit time of the head of our solid meal. Thus the effect on the small bowel did not occur secondary to an action on the delivery of food from the stomach, but was probably related instead to a direct effect on the motor activity of the small intestine. Schemann and Ehrlein" have previously reported that cisapride stimulates perstaltic activity in the canine small intestine after ingestion of food.
Cisapride also accelerated whole gut transit and increased stool output and frequency in the majority of subjects, confirming the impression gained from previous studies in man using barium pills. ${ }^{2}$ In the dog the acceleration of transit time has been shown in association with the generation of premature propagating colonic motor patterns. ${ }^{2}$ The effects on the colon may be a direct action of cisapride or may be secondary to an increased rate of entry of material from the ileum. We have previously shown that acceleration of small bowel transit in patients with ileostomies by drugs is associated with an increased flow of ileal effluent, ${ }^{10}$ and there is evidence to suggest that an increased rate of entry of fluid into the colon is associated with the generation of propagated colonic contractions. ${ }^{11}$ Despite these considerations, domperidone has not been shown to alter colonic transit in man, although it accelerates transit through the small intestine. ${ }^{12}$

\section{References}

1 Reyntjens A, Verlinden M, De Coster R, et al. Clinical pharmacological evidence for cisapride's lack of antidopaminergic or direct cholinergic propertics. Curr Ther Res 1984; 36: 1045-52.

2 Lee KY, Chey WY, You CH, Shah AN, Hamilton D. Effect of cisapride on the motility of gut in dogs and colonic transit time in dogs and humans. Gastroenterology 1984; 86: 1157.

3 Suzuki T, Nakaya M, Arai H, Wakabayashi K, Itoh Z. Characteristic motor stimulating effect of cisapride on gastrointestinal tract in conscious dogs. Gastroenterology 1984; 86: 1271.

4 Reboa G, Arnulfo G, di Somma C, et al. Prokinetic effects of cisapride on normal and reduced antroduodenal motility and reflexes. Curr Ther Res 1984; 36: 18-23.

5 Read NW, Miles CA, Fisher D, et al. Transit of a meal through the stomach, small intestine and colon in 
normal subjects and its role in the pathogenesis of diarrhoea. Gastroenterology 1980; 79: 1276-82.

6 Van Daele L, De Cuypere A, Van Kerckhove M. Routine radiological follow-through examination shows effect of cisapride on gastrointestinal transit: a controlled study. Curr Ther Res 1984; 36: 1038-44.

7 Corinaldesi R, Stanghellini V, Zarabini GE, et al. Effects of cisapride on gastric emptying of solids in dyspeptic patients. [Abstract]. Gut 1984; 25: A1307.

8 Jian R, Ducrot F, Piedeloup C, Mary JY, Najean Y, Bernier JJ. Measurement of gastric emptying in dyspeptic patients: effect of a new gastrokinetic agent (cisapride). Gut 1985; 26: 352-8.
9 Schemann M, Ehrlein HJ. Cisapride stimulates peristaltic activity of the canine jejunum during the digestive period. [Abstract]. Gut 1984; 25: A1310.

10 Holgate AM, Read NW. Relationship between small bowel transit time and absorption of a solid meal. Influence of metoclopramide, magnesium sulphate and lactulose. Dig Dis Sci 1983; 28: 812-9.

11 Chauve A, Devroede G, Bastin E. Intraluminal pressures during perfusion of the human colon in situ. Gastroenterology 1976; 70: 336-40.

12 Cann PA, Read NW. Holdsworth CD. Oral domperidone: double blind comparison with placebo in irritable bowel syndrome. Gut 1983; 24: 1135-40. 